\title{
PERANCANGAN ALAT PENINGKATAN KADAR FLUOR AIR SUNGAI MENGGUNAKAN METODE KONTAK BEBATUAN MENGANDUNG FLUOR DI DESA MEKAR SARI KECAMATAN TATAH MAKMUR KABUPATEN BANJAR
}

\author{
PLANNING OF RIVER WATER FLUORIDE IMPROVEMENT EQUIPMENT USING \\ CONTACT METHOD OF FLUORINE-CONTAINING ROCKS IN MEKAR SARI \\ VILLAGE TATAH MAKMUR DISTRICT BANJAR REGENCY
}

\author{
Ida Rahmawati ${ }^{*}$, Fahmi Said ${ }^{2}$, Abdul Haris ${ }^{3}$ \\ 1,2,3 Politeknik Kesehatan Banjarmasin, \\ Jl. Garuda No.21 Banjarbaru. Kalimantan Selatan. Indonesia \\ *Email: idarahmawati102@gmail.com
}

\begin{abstract}
The fluoride content in the water consumed by the people of Mekar Sari Village, Tatah Makmur District, Banjar Regency is still below the WHO recommendation (2004) with minimum of $0.5 \mathrm{mg} / \mathrm{l}$ and the Regulation of the Minister of Health of the Republic of Indonesia 492/2010 a maximum of 1.5 $m g / l$. From a preliminary survey conducted on the water content of the Tatah Makmur River, it shows that the fluoride content is $0.08 \mathrm{mg} /$. The purpose of this research is to determine the fluoride content of treated river water after contact with rocks containing fluoride. This type of research is an experiment with descriptive data processing techniques. Experiments were carried out on river water by pre-treatment until the turbidity was less than 5 NTU. The treated water is then recirculated into a portable fluorine increase apparatus to engineer the contact of the treated water with fluoridated rocks. Variations in this study consisted of variations in the duration of recirculation 6 hours, 12 hours, 24 hours, 48 hours, and 72 hours; the thickness of the rocks is $10 \mathrm{~cm}, 20 \mathrm{~cm}, 30 \mathrm{~cm}, 40 \mathrm{~cm}$, and $50 \mathrm{~cm}$, the fluorine rocks used are 1-2 cm in size. The conclusion of this study is that treated water is passed through fluoride rock, which is the highest increase in rock with a thickness of $50 \mathrm{~cm}$ indicating fluorine content from $0.08 \mathrm{mg} / \mathrm{l}$ (initial) to $0.24-0.69 \mathrm{mg} / \mathrm{l}$ and the lowest increase in rock. with a thickness of $10 \mathrm{~cm}$ from $0.08 \mathrm{mg} / \mathrm{l}$ (initial) to $0.31-0.56 \mathrm{mg} / \mathrm{l}$ Suggestions to be able to apply fluorine enrichment technology in Tatah Makmur river water, further trials need to be carried out on other types of fluorine rocks.
\end{abstract}

Keywords: River Water; Rock; Fluor

\begin{abstract}
ABSTRAK
Kandungan fluoride dalam air yang dikonsumsi masyarakat Desa Mekar Sari Kecamatan Tatah Makmur Kabupaten Banjar masih dibawah rekomendasi WHO (2004) minimal 0,5 mg/l dan Peraturan Menteri Kesehatan RI 492/2010 maksimal 1,5 mg/l. Dari survey pendahuluan yang dilakukan terhadap kandungan air sungai Tatah Makmur menujukkan kandungan fluorida sebesar $0,08 \mathrm{mg} / \mathrm{l}$. Penelitian ini bertujuan untuk mengetahui kadar fluorida air sungai terolah setelah dilakukan kontak bebatuan mengandung fluoride. Jenis penelitian adalah eksperimen dengan teknik pengolahan data secara deskriptif. Eksperimen dilakukan pada air sungai dengan cara dilakukan pengolahan pendahuluan sampai kekeruhan kurang dari 5 NTU. Selanjutnya air terolah diresirkulasi ke dalam suatu peralatan fluor increase portable untuk merekayasa kontak air terolah dengan bebatuan mengandung fluorida. Variasi pada penelitian ini terdiri dari variasi lama resirkulasi 6 jam, 12 jam, 24 jam, 48 jam, dan 72 jam; tebal bebatuan $10 \mathrm{~cm}, 20 \mathrm{~cm}, 30 \mathrm{~cm}, 40 \mathrm{~cm}$, dan $50 \mathrm{~cm}$, batuan fluor yang digunakan berukuran 1-2 cm. Kesimpulan dari penelitian ini yaitu air terolah yang dilewatkan pada batuan fluoride yaitu peningkatan tertinggi pada batu dengan tebal $50 \mathrm{~cm}$ menunjukkan kandungan fluor dari 0,08 mg/l (awal) menjadi 0,24 - 0,69 mg/l dan peningkatan terendah pada batu dengan tebal $10 \mathrm{~cm}$ dari 0,08 mg/l (awal) menjadi 0,31 0,0,56 mg/l. Saran untuk dapat menerapkan teknologi pengayaan fluor dalam air sungai Tatah Makmur perlu dilakukan uji coba lanjutan pada jenis batuan fluor yang lain.
\end{abstract}

Kata Kunci: Air Sungai; Batuan; Fluor 


\section{PENDAHULUAN}

Fluoride merupakan zat kimia yang dapat ditemukan di alam bebas, dengan kadar 0,3 gram fluoride dalam setiap $1 \mathrm{~kg}$ penyusun kulit bumi. Fluoride bisa ditemukan dalam air minum secara alami atau karena ditambahkan dengan sengaja oleh produsen. Secara alami tinggi rendahnya kandungan fluoride pada air minum tergantung dari batuan dan mineral yang dilewatinya. Setelah diminum atau dimakan, hampir seluruh fluoride akan diserap oleh pencernaan kita, masuk aliran darah, dan disimpan di tulang atau gigi (1).

Survey pendahuluan yang dilakukan terhadap kandungan fluoride pada air sungai Desa Mekar Sari Kecamatan Tatah Makmur menunjukkan kandungan fluoride sebesar $0,08 \mathrm{mg} / \mathrm{l}$. Ini masih jauh dari persyaratan kandungan air minum yang dapat menguatkan gigi. Dosis fluoride dalam air minimum minimal $0,5 \mathrm{mg} / 1$ dan maksimum $1,5 \mathrm{mg} / 1(2,3)$. Rentang dosis tersebut cukup untuk memberikan efek yang baik bagi tulang dan gigi. Namun, dosis yang berlebihan justru dapat menyebabkan kerusakan tulang dan gigi. Fluorosis gigi kelainan enamel yang disebabkan oleh konsumsi fluoride yang berlebihan terjadi apabila kandungan fluoride dalam air berkisar antara 1,5 - $2 \mathrm{mg} /$ liter, tergantung seberapa banyak seseorang meminum air tersebut. Fluorosis gigi sering terjadi pada usia anak 22-26 bulan di mana terjadi pertumbuhan dan mineralisasi gigi. Selain itu, konsumsi berlebihan juga dapat menyebabkan keracunan fluoride akut yang bisa terjadi apabila mengkonsumsi fluoride sebanyak $>1 \mathrm{~g}$ setiap $\mathrm{kg}$ berat badan.

penelitian ini untuk mengetahui kadar fluor air sungai terolah setelah dilakukan kontak bebatuan mengandung fluor Di Desa Mekar Sari Kecamatan Tatah Makmur Kabupaten Banjar Provinsi Kalimantan Selatan.

\section{BAHAN DAN METODE}

Berdasarkan analisis datanya penelitian ini merupakan penelitian deskriptif, sedangkan jenis penelitian adalah eksperimen. Variabel yang terlibat dalam penelitian ini meliputi variabel terikat dan variabel bebas. Variabel terikat adalah air sungai Mekar Sari, dan variable bebas adalah ketebalan media terbagi menjadi $10 \mathrm{~cm}, 20 \mathrm{~cm}, 30 \mathrm{~cm}, 40 \mathrm{~cm}$, dan $50 \mathrm{~cm}$; besar media meliputi ukuran media $1 \mathrm{~cm}$ sampai $2 \mathrm{~cm}$; dan waktu kontak merupakan lamanya pengaliran air terolah melewati media bebatuan selama 6 jam, 12 jam, 24 jam, 48 jam, dan 72 jam. Sampel penelitian adalah air sungai Desa Mekar Sari Kecamatan Tatah Makmur Kabupaten Banjar Provinsi Kalimantan Selatan. Teknik pengambilan data diperoleh dengan cara pengambilan sampel secara langsung pada air sungai Mekar Sari untuk diturunkan kekeruhannya sampai memenuhi syarat air minum yakni 5 NTU.

Penurunan kekeruhan menggunakan larutan tawas $2 \%$. Untuk menentukan dosis tawas optimum dilakukan uji Jar-Test. Hasil intervensi peningkatan kandungan fluoride diperoleh dengan cara melewatkan air baku terolah pada Fluor Increase Portable dengan variasi ketebalan media, besar media, dan lama kontak. Jumlah pengulangan sebanyak 1 kali. Total jumlah data sebanyak 27 data terdiri dari 1 data kandungan fluor pada air terolah, 1 data kandungan fluor pada air rendaman batu, dan 25 data kandungan fluor hasil uji coba increase fluor set. Setelah air terolah melewati lapisan bebatuan pada alat fluor increase portable sesuai variasi di atas, maka diambil sampel sebanyak $50 \mathrm{ml}$ untuk diperiksakan pada laboratorium uji, untuk dilihat peningkatan kandungan fluor pada air terolah.

Fluoride terjadi secara alami dalam kerak bumi dan ditemukan dalam bebatuan. Batu fluoride (4). yang digunakan merupakan batu lokal yang terdapat di daerah Gambut-Liang Anggang Kabupaten Banjar. Pemilihan batu ini selain harganya relatif murah, batu ini juga merupakan batuan yang dekat dengan daerah lokasi penelitian di Tatah Makmur Kabupaten Banjar. Sifat fluor yang putih terlihat pada batuan ini bila dilakukan pemecahan. Batu fluoride putih pecah secara manual dengan ukuran $1-2 \mathrm{~cm}$.

Sebelum dimasukkan ke dalam alat Fluoride Increase Potable (FIP), batuan fluoride yang berwarna putih dicuci terlebih dahulu dengan cara dimasukkan ke dalam air bersih. Langkah selanjutnya, batu fluoride dalam bentuk padat yang sudah bersih dimasukkan ke dalam FIP dengan ketebalan $10 \mathrm{~cm} ; 20 \mathrm{~cm} ; 30 \mathrm{~cm} ; 40 \mathrm{~cm}$; dan $50 \mathrm{~cm}$.

Selanjutnya dilakukan pemasangan FIP ke dalam aliran sirkulasi air terolah. Masing-masing tandon air 150 liter diisi dengan air terolah sebanyak 40 liter. sirkulasi dilakukan selama 6 jam; 12 jam; 24 jam; 48 jam; dan 72 jam. Total variasi untuk jenis batu fluoride putih sebanyak 25 variasi dapat dilihat pada Tabel 1.

Air baku dari Sungai Tatah Makmur Kabupaten Banjar, diangkut ke tempat pengolahan pendahaluan di Komplek Kesehatan Banjarbaru. Selanjutnya dilakukan uji coba Jar-Test untuk menentukan dosis tawas. Dosis tawas optimum dipergunakan untuk menurunkan kekeruhan air baku sampai memenuhi syarat kualitas air bersih menurut Permenkes RI No. 492 Tahun 2010 tentang Persyaratan Kualitas Air Minum, yakni 5 NTU. Untuk menentukan dosis tawas optimum untuk menurunkan kekeruhan air dilakukan uji Jar-Test. ${ }^{5}$ Hasil uji Jar-Test didapatkan dosis optimum untuk menurunkan kekeruhan air Sungai Tatah Makmur 
Kabupaten Banjar adalah larutan tawas $2 \%$ sebanyak $2 \mathrm{ml} /$ liter air sampel. Air Sungai Tatah Makmur yang diangkut menggunakan truk pengangkut air, dimasukkan ke dalam 3 buah tandon air masingmasing kapasitas 1200 liter. Satu tandon air berisi 1200 liter dibubuhi larutan tawas 2\% sebanyak 2400 $\mathrm{ml}$ kemudian diaduk menggunakan submercibel atu pompa celup selama 15 menit, selanjutnya didiamkan selama 3 jam $(5,6)$.

Langkah selanjutnya memasukkan air terolah sebanyak masing-masing 40 liter ke dalam 5 buah bak penampungan berupa tandon kapasitas 150 liter. masing-masing bak penampungan tersebut terhubung dengan fluor increase portable, selang, pompa celup akuarium, dan aliran listrik 220 Volt. Selanjutnya air dalam tendon tersebut diresirkulasi selama 6 jam, 12 jam, 24 jam, 48 jam, dan 72 jam.

Hasil uji laboratorium terhadap kandungan fluor yang larut dalam air terolah, dapat dilihat pada Tabel 1.

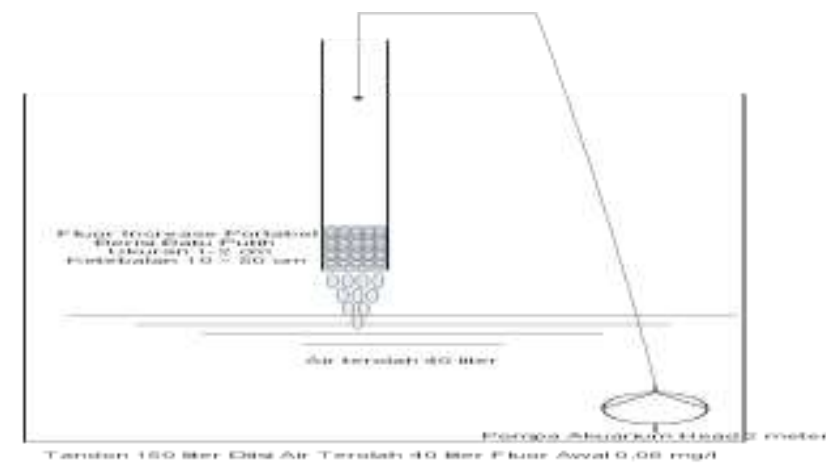

Gambar 1. Fluoride Increase Portable Yang Terpasang Pada Rangkaian Uji Coba

Pada Gambar 1 diperlihatkan rangkaian peralatan pada saat running alat fluor increase portable untuk meningkatkan kandungan fluor pada air terolah dari kandungan awal 0,08 mg/1 fluor. Setelah melalui serangkaian uji coba, kandungan fluor dalam air terolah dapat ditingkatkan seperti disajikan dalam Tabel 1.

HASIL DAN PEMBAHASAN

Tabel 1. Kondisi pH, Fluoride, dan Kekeruhan Air Terolah dan Air Rendaman Batu

$\begin{array}{lllll}\text { No } & \text { Parameter } & \text { Satuan } & \text { Air Rendaman Batu } & \text { Air Terolah }\end{array}$

\begin{tabular}{lccccc}
1 & Ph & - & 6,58 & 4,7 & $6,5-8,5$ \\
2 & Fluorida & mg/1 & 2,12 & $\mathbf{0 , 0 8}$ & 1,5 \\
3 & Kekeruhan & NTU & - & 2,85 & 5 \\
\hline
\end{tabular}

Sumber: Laporan Hasil Uji No.036 dan 049; (data primer)

Dari Tabel 1 diatas, dapat diketahui bahwa kandungan fluor pada air rendaman batu (selama 1 bulan) sebesar 2,12 mg/l. ini tentu tidak layak untuk dikonsumsi karena mengandung fluor melebihi ambang batas yang disarankan sekitar 1 - 1,5 mg/liter fluor dalam air minum atau berkisar 0,7 - 1,2 mg/1 (7,8). Rendaman batu yang terlalu lama menyebabkan kandungan fluor yang melebihi kisaran 1,7 mg/l dapat mengakibatkan pewarnaan pada enamel gigi, yang dikenal dengan istilah mottling $(8,9,10)$. Kadar yang berlebihan dapat berimplikasi pada terhadap kerusakan pada tulang selama proses pembentukan gigi pada bayi (10).

Pada air terolah, kandungan fluor menunjukkan kadar 0,08 mg/l. Ini merupakan kandungan fluor yang sangat kecil, sehingga bila dikonsumsi terus-menerus akan menimbulkan karies atau gangguan pertumbuhan gigi $(2,10,11)$.

Untuk meningkatkan kadar fluor dalam air minum (air terolah yang telah jernih) dapat dilakukan dengan cara melewatkan pada media batu yang mengandung fluor. Studi pendahuluan, batu putih yang berasal dari daerah sekitar Gambut sampai Liang Anggang memiliki kandungan fluor. Dengan cara perendaman, batu putih Gambut-Liang Anggang menunjukkan kandungan fluor sebesar 2,12 mg/1.

Setelah dilakukan intervensi berupa pengaliran air terolah (kadar fluor awal 0,08 mg/1) pada media bebatuan yang terdapat pada Fluor Increase Portable dengan variasi lama pengaliran (6 jam, 12 jam, 24 jam, 48 jam, dan 72 jam); tebal lapisan bebatuan $(10 \mathrm{~cm}, 20 \mathrm{~cm}, 30 \mathrm{~cm}, 40$, cm, dan $50 \mathrm{~cm})$; serta besar butiran batu (1-2 $\mathrm{cm})$ menunjukkan hasil yang dapat dilihat pada Tabel 2. 
Tabel 2. Pengaruh Ketebalan Batuan Butiran 1-2 cm Dan Waktu Kontak Terhadap Konsentrasi Fluor Dalam Air

\begin{tabular}{|c|c|c|c|c|c|}
\hline \multirow{2}{*}{$\begin{array}{l}\text { Tebal } / \text { Waktu } \\
\text { Waktu } / \text { Kontak }\end{array}$} & & & & & \\
\hline & $6 \mathrm{Jam}$ & $12 \mathrm{Jam}$ & $24 \mathrm{Jam}$ & 48 Jam & 72 Jam \\
\hline $10 ; 1-2^{\prime}$ & 0.31 & 0.3 & 0.46 & 0.58 & 0.56 \\
\hline $20 ; 1-2$ & 0.27 & 0.35 & 0.48 & 0.59 & 0.61 \\
\hline $30 ; 1-2$ & 0.25 & 0.35 & 0.47 & 0.61 & 0.63 \\
\hline $40 ; 1-2$ & 0.32 & 0.41 & 0.46 & 0.64 & 0.66 \\
\hline $50 ; 1-2$ & 0.24 & 0.31 & 0.39 & 0.66 & 0.69 \\
\hline
\end{tabular}

Sumber: Laporan Hasil Uji 041/LHU/BBTKL-BB/IX/2017

Telah dikemukakan pada Tabel 1 bahwa fluor dalam air terolah adalah $0,08 \mathrm{mg} /$ liter. Bila dilihat Tabel 2 kadar fluor air terolah pada semua variasi ketebalan bebatuan butiran $1-2 \mathrm{~cm}$ dan variasi lama kontak air terhadap bebatuan, menunjukkan peningkatan di setiap jamnya. Peningkatan konsentrasi fluor terendah ada pada variasi waktu kontak 6 jam pada ketebalan $30 \mathrm{~cm}$ bebatuan butiran $1-2 \mathrm{~cm}$. Peningkatan prosentasi peningkatan fluor pada variasi $6 \mathrm{~J} ; 30 \mathrm{~cm}$; butiran 1-2 $\mathrm{cm}$ dapat ditentukan sebagai berikut:

$$
\begin{aligned}
\mathrm{PPF} & =\left(\mathrm{K}_{\mathrm{ft}} / \mathrm{K}_{\mathrm{af}}\right) \times 100 \% \\
& =(0,25 / 0,08) \times 100 \% \\
& =312,5 \%
\end{aligned}
$$

Dimana:

PPF = Prosentasi Peningkatan Fluor

$\mathrm{K}_{\mathrm{ft}} \quad=$ Konsentrasi fluor terakhir pada suatuvariasi

$\mathrm{K}_{\mathrm{af}} \quad=$ Konsentrasi awal fluor pada air terolah

Dari perhitungan di atas dapat dikatakan bahwa besarnya peningkatan fluor terendah terjadi pada variasi $6 \mathrm{Jam} ; 30 \mathrm{~cm}$; butiran 1-2 $\mathrm{cm}$ yakni sebesar 312,5\%. Dengan perhitungan yang sama, prosentasi tertinggi peningkatan fluor pada air terolah terjadi pada variasi $72 \mathrm{jam} ; 50 \mathrm{~cm}$; butiran $1-2 \mathrm{~cm}$ yakni $0,69 \mathrm{mg} / 1(862,5 \%)$.

Dari Tabel 2 di atas dapat dilihat bahwa peningkatan konsentrasi fluor terjadi pada semua variasi ketebalan batuan berukuran 1-2 cm. Pada interval waktu kontak air terolah pada batuan yang mengandung fluor terjadi peningkatan yang sangat tajam dari 6 jam sampai 48 jam. Pada saat waktu kontak ditambah sampai 48 jam, proses peningkatan fluor mulai melambat. Ini patut diduga bahwa kandungan fluor pada bebatuan yang dapat larut pada air terolah mulai berkurang.

Kondisi seperti ini hampir semua terjadi pada suatu penelitian eksperimental, seperti yang dilakukan oleh (12) bahwa yang melakukan uji coba penurunan polutan udara menggunakan wet scrubber. pada waktu tertentu, setelah running alat beberapa waktu, maka efektivitas dan efisiensi peralatan mulai melambat dan stagnan atau stabil. Ini menunjukkan bahwa peralatan sudah mulai jenuh. Demikian pula dengan peluruhan fluor dalam batuan putih berukuran 1-2 cm, diduga sudah mulai jenuh atau tidak dapat lepas lagi dari ikatan awal (ikatan pada partikel batu $(12,13)$.

Kandungan fluor dalam batu putih yang mulai berkurang setelah waktu kontak melebihi 3 hari tersebut, memberikan konsekuensi penggantian batu putih agar proses kontak antara bebatuan fluor dan air terolah dapat dilakukan secara kontinyu. Proses kontinyu diperlukan untuk memastikan air yang dikonsumsi masyarakat desa Tatah Makmur Kabupaten Banjar memenuhi kebutuhan fluoride dalam air minum. Proses penggantian batu putih setelah 3 hari dikhawatirkan mengurangi tingkat penerimaan masyarakat terhadap teknologi peningkatan kandungan fluor dalam air terolah menggunakan batu putih, dengan alasan kurang praktis.

\section{KESIMPULAN DAN SARAN}

Air terolah yang dilewatkan pada batuan fluorid yaitu peningkatan tertinggi pada batu dengan tebal $50 \mathrm{~cm}$ menunjukkan kandungan fluor dari 0,08 mg/l (awal) menjadi 0,24 - 0,69 mg/l dalam waktu 6-72 jam dan peningkatan terendah pada batu dengan tebal $10 \mathrm{~cm}$ dari $0,08 \mathrm{mg} / 1$ (awal) menjadi 0,31 - 0,0,56 mg/1 dalam waktu 6-72 jam. Pada kondisi tertentu setelah proses air terolah melewati lapisan bebatuan dan seiring berjalannya waktu, maka kandungan fluor dalam batuan fluoride tidak bisa lagi dilarutkan ke dalam air terolah yang melewati fluor increase portable. Untuk dapat menerapkan teknologi pengayaan fluor dalam air sungai Tatah Makmur perlu dilakukan uji coba lanjutan pada jenis batuan fluor yang lain. Ini disebabkan batuan putih yang mengandung fluor dari daerah Gambut-Liang Anggang memiliki kandungan fluor yang rendah. Ini terindikasi dengan tidak terjadinya penambahan kandungan fluor pada waktu kontak 48 jam ke 72 jam. Dapat dikatakan bahwa fluor yang dapat larut di air pada batuan putih sudah 
menipis, sehingga bila dilakukan penambahan waktu (dengan tujuan pemakaian lebih lama), maka fluor tak dapat lagi luruh ke air. Untuk Dinas Kesehatan membuat program proses kontinyu untuk memastikan air yang dikonsumsi masyarakat desa Tatah Makmur Kabupaten Banjar memenuhi kebutuhan fluoride dalam air minum

\section{UCAPAN TERIMA KASIH}

Ucapan terima kasih disampaikan kepada Kementerian Kesehatan Re publik Indonesia yang telah memberikan dukungan biaya dalam penelitian. Ucapan terima kasih juga disampaikan kepada masyarakat Desa Mekar Sari Kecamatan Tatah Makmur Kabupaten Banjar Propinsi Kalimantan selatan. Terakhir diucapkan terima kasih atas advis keilmuan kepada Saudara Abdul Haris, S.KM.,M.T dan Saudara Adiansyah, A.Md; dosen dan staf laboratorium Jurusan Kesehatan Lingkungan Poltekkes Banjarmasin, Saudara Muhammad Baihaqi, S.Si.,M.Si dan Saudari Suyatmi, A.Md staf pada Laboratorium Kimia Balai Besar Teknik Lingkungan dan Pengendalian Penyakit Banjarbaru.

\section{DAFTAR PUSTAKA}

1. Hamdi, Fadhil. Identifikasi dan Pemetaan Kualitas Air Tanah di Kota Surabaya. Diss. Institut Teknologi Sepuluh Nopember, 2018.

2. Word Health Organization. Pedoman Mutu air Minum (Judul Asli: Guidenes for DrinkingWater Quality ; Third Edition), EGC-Penerbit Buku Krdokteran: Jakarta, 2011; p: 555-558.

3. Peraturan Menteri Kesehatan RI No. 492/Menkes/Per/IV/2010 tentang Persyaratan Kualitas Air Minum.

4. ATSRD. Toxicological Profile for Flourides, Hydrogen Flouride, and Flourine. United States Department of Health and Human Services. Atlanta, Georgia, 2003.

5. Hermana J, Voijant B, Samodra A. Penuntun Praktikum Metoda Analisis Pencemar Lingkungan. Laboratorium Teknologi Lingkungan Jurusan Teknik Lingkungan FTSPITS, Surabaya. 2006.

6. Eckenfelder.Jr. Industrial Water Pollution Control - Thrird Edition, Mc Graw-Hill Series in Water Resource and Environmental Engineering, 2000; p:85-103.

7. Notoatmodjo S, 2010, Metodelogi Penelitian Kesehatan, Renika Cipta, Jakarta, p:40.

8. Davis, M.L. dan Cornwell, D.A. Introduction to Environmental Engineering. Second Edition. Mc Graw Hill, Inc, New York; 1991.
9. Effendi H. Telaah Kualitas Air Bagi Pengelolaan Sumber Daya dan Lingkungan Perairan, Jakarta, 2003; p: 30,42.

10. Mukono. Toksikologi Lingkungan, Airlangga University Press: Surabaya, 2005; p: 221.

11. Haris.A. Penurunan Debu Padi Menggunakan Wet Scrubber, Tesis: Teknik Lingkungan ITS, Surabaya, 2011; p:45-47.

12. Husaini dan Haris. Sulfur Dioxide Removal of Smoke Area in Rubber Sheet Industri Using Wet Scrubber, IJABER, 2016; Vol. 14, No.5 p:2817-2830. 